\title{
High-Resolution Measurements of Scattering in Wheat Canopies-Implications for Crop Parameter Retrieval
}

\author{
Sarah C. M. Brown, Shaun Quegan, Member, IEEE, Keith Morrison, Member, IEEE, John C. Bennett, and
} Geoff Cookmartin

\begin{abstract}
Polarimetric X-and C-band measurements by the University of Sheffield ground-based synthetic aperture radar (GB-SAR) indoor system provide three-dimensional images of the scattering processes in wheat canopies, at resolutions of around a wavelength $(3-6 \mathrm{~cm})$. The scattering shows a pronounced layered structure, with strong returns from the soil and the flag leaves, and in some cases a second leaf layer. Differential attenuation at horizontal $(\mathrm{H})$ and vertical $(\mathrm{V})$ polarization, due to the predominantly vertical structure of the wheat stems, gives rise to marked effects. At both $C$ and $X$ bands, direct return from the canopy exceeds the soil return at large incidence angles for $\mathrm{VV}$ polarization, but is comparable to or less than the soil return in all other cases. At HV, the apparent ground return is probably due to a double-bounce mechanism, and volume scattering is never the dominant term. Direct sensing of the crop canopy is most effective at $X$ band, $V V$, and large incidence angles, under which conditions the return is dominated by the flag leaf layer. Field measurements with the outdoor GB-SAR system suggest, however, that for sensitivity to biomass and reduced susceptibility to disturbances by rainfall, a two-channel $\mathrm{C}$-band system operating at a medium range of incidence angles is preferred.
\end{abstract}

Index Terms-Agriculture, backscatter modeling, synthetic aperture radar (SAR).

\section{INTRODUCTION}

$\mathbf{M}$ ANY EXPERIMENTAL studies, using scatterometers [1]-[5], airborne [6]-[9], and spaceborne [10], [11] radars have demonstrated that the backscatter from wheat (and other agricultural crops) is significantly affected by the state of the crop canopy. Interpretation of these observations has largely relied on models. Particularly fruitful use was made of the water cloud model [12] to explain many of the features in extended multitemporal studies with the French ground-based scatterometer systems (RAMSES) [1], [13]-[15]. In particular, these studies argued that in the earlier parts of the growing season, the radar was essentially measuring an attenuated soil

Manuscript received March 26, 2002; revised May 1, 2003. This work was supported by the U.K. BNSC/LINK programme (Project R4/025) and by the Natural Environmental Research Council (Reference DST/26/61).

S. C. M. Brown was with the Sheffield Centre for Earth Observation Science, University of Sheffield, Sheffield S3 7RH, U.K. She is now with the Advanced Technology Centre, BAE Systems, Chelmsford, Essex CM2 8HN, U.K.

S. Quegan, J. C. Bennett, and G. Cookmartin are with the Sheffield Centre for Earth Observation Science, University of Sheffield, Sheffield S3 7RH, U.K.

K. Morrison was with the Sheffield Centre for Earth Observation Science, University of Sheffield, Sheffield S3 7RH, U.K. He is now with the Department of Aerospace, Power and Sensors, Cranfield University, Royal Military College of Science, Shrivenham, Swindon SN6 8LA, U.K.

Digital Object Identifier 10.1109/TGRS.2003.814132 return. Later in the growth cycle, scattering by leaves could dominate, leading to differences between the responses from wheat varieties with different structure. It was also argued and confirmed that canopy volumetric water content and leaf area index (LAI) should be correlated with $\sigma^{0}$ for wheat crops. A conclusion of these studies was that the optimal system for monitoring wheat would operate at $X$ band with vertical-vertical (VV) polarization and incidence angles around $40^{\circ}$. Only the Spaceborne Imaging Radar-C/X-band Synthetic Aperture Radar (SIR-C/X-SAR) mission in 1994 has provided extensive $\mathrm{X}$-band VV data to test these conclusions, since most available airborne and spaceborne data have been at longer wavelengths. However, the timing of the SIR-C acquisitions (April and October) was not ideal in terms of crop development, and little has been reported on this topic. The value of C-band data for wheat crop monitoring and biomass estimation has, meanwhile, been demonstrated in a number of studies [8]-[11]. Here, we report on the use of multiparameter radar to investigate these issues and to recover two particularly important agronomical wheat parameters, biomass and green area index (GAI), that are hard to measure by other means. The study is based on two multitemporal measurement campaigns carried out during 1999 and 2000.

The main contribution of the 1999 indoor campaign was to provide, for the first time, three-dimensional (3-D) radar measurements with sufficient resolution to localize the scattering processes within a wheat canopy. Previous radar measurements have used sensors with much coarser resolutions than the scattering elements in the crop. Their interpretation has, therefore, relied on models that have become progressively more sophisticated [5], [10], [12], [16], but which still employ very simplified representations of the canopy and its interaction with the radar wave. Since wheat canopies contain a complex mixture of components (stems, leaves, ears) with strong vertical structure in the stems and ears, it is not clear that the models adequately capture the overall behavior of scattering and attenuation involved in the radar response. The 1999 indoor campaign was specifically designed to measure and visualize the true nature of microwave scattering within a wheat canopy.

While the indoor campaign aimed at fundamental understanding of the radar response from a wheat canopy, the 2000 outdoor campaign was more concerned with elucidating how the radar return is related to biomass and GAI. To this end, multitemporal measurements of wheat canopies under a range of field conditions were gathered across the growing season. 
It should be noted that the experimental results in this paper were supported by a parallel modeling study. Indeed, the ground measurements were specifically designed to provide the data necessary to drive a second-order radiative transfer model (RT2) [10]. Here, we have avoided detailed comparison with the model calculations because we found significant disagreements between the measurements and the model [17]. These can, in part, be attributed to incorrect representation of attenuation by the model, particularly for vertical polarization, where the attenuation is significantly overestimated. This is due to the inadequacy of the forward scattering theorem for calculating the attenuation in a wheat canopy, which cannot be considered as a sparse medium [18]. This defect is not specific to RT2; almost all the published papers dealing with wheat models use this method to calculate the attenuation (e.g., [5] and [16]). However, the associated errors are not revealed as starkly as in the current experiments, because the airborne and spaceborne measurements used for comparison with the models do not resolve the details of the scattering in the canopy. Since they are integrations through the canopy, they average the various scattering terms together and cannot distinguish between alternative weightings of terms that could produce the same total backscatter. In the indoor measurements described in this paper, these weightings are measured and in many cases disagree with the model calculations. Hence, although we make reference to such calculations, we cannot make reliable use of them to interpret the measurements.

\section{INDOOR EXPERIMENTS}

The ground-based synthetic aperture radar (GB-SAR) indoor microwave facility at the University of Sheffield [19] is housed in a $6 \mathrm{~m} \times 4 \mathrm{~m} \times 3 \mathrm{~m}$ chamber internally covered with radar-absorbing material. It contains a roof-mounted rectangular planar scanning frame holding four closely spaced horn antennas, with one transmit and one receive antenna for both vertical $(\mathrm{V})$ and horizontal $(\mathrm{H})$ polarizations. A vector network analyzer provides swept-frequency signals at each position during two-dimensional scans of the antenna cluster. The stored returns are used to reconstruct 3-D, polarimetric imagery of targets imported into the chamber on a computer-controlled trolley. The approximate imaging geometry is shown in Fig. 1; this varied slightly in a known way between experiments. Aperture sizes used for this experiment were $71.5 \mathrm{~cm} \times 166.1 \mathrm{~cm}$ at $\mathrm{X}$ band and $98 \mathrm{~cm} \times 175 \mathrm{~cm}$ at $\mathrm{C}$ band. The antennas have sufficient beamwidth to simultaneously illuminate the whole target region. Very high resolutions can be achieved with the imaging algorithm [20]: the images described below have resolutions of around one to one and a half wavelengths in each dimension.

Calibration to radar cross section (RCS) is based on measurements of a sphere and a depolarizing target, as described in [21]. Note that RCS, rather than normalized backscatter $\left(\sigma^{0}\right)$, is the most appropriate measure at the very high resolution of the data. The system has a minimum detectable RCS better than $-75 \mathrm{~dB} \mathrm{~m}^{-2}$ at $\mathrm{C}$ band.

Wheat samples (spring wheat, variety Chablis) were hand-sown in plastic containers measuring $58 \times 39 \times 25 \mathrm{~cm}$ in March 1999 and were then exposed to normal outdoor growing conditions in the U.K. The soil in the boxes was Kettering

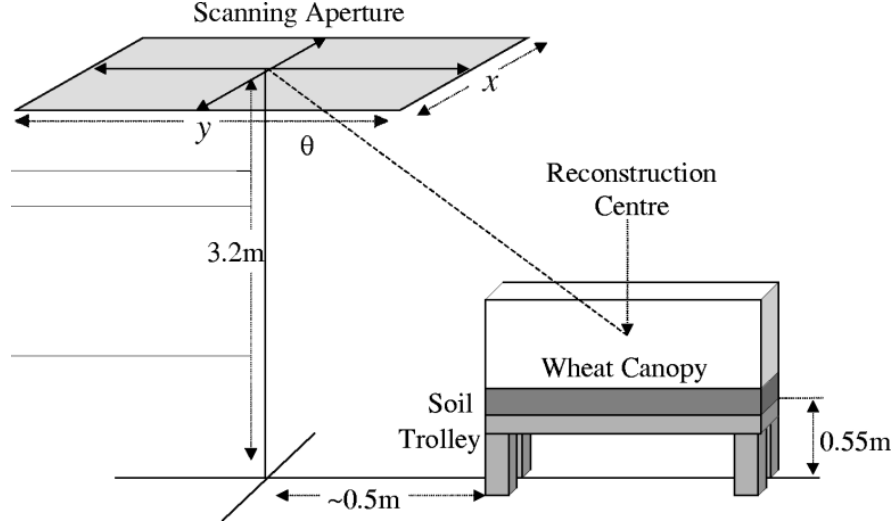

Fig. 1. Geometry of indoor measurements, illustrating a scanning aperture over a wheat canopy on the trolley. The height of the base of the trolley is $55 \mathrm{~cm}$, and the soil depth is $25 \mathrm{~cm}$.

loam, composed of $41 \%$ sand, $37 \%$ silt, and $22 \%$ clay and was $25 \mathrm{~cm}$ in depth. At regular intervals throughout the growing season, batches of containers were delivered to the University of Sheffield. After removing the rims from the containers, they were packed tightly together on the trolley to form a wheat canopy $1.56 \mathrm{~m} \times 1.74 \mathrm{~m}$ in size. Spaces around and between the containers were filled with spare soil to ensure there were no visible gaps or large irregularities in the soil surface. The trolley was then moved into the anechoic chamber in order to make the microwave measurements.

Agronomic and architectural parameters were collected from the wheat and soil for each canopy. The agronomic data comprised measurements of green area index (using a LICOR plant canopy analyzer), and shoot number (the agronomic term "shoot number" indicates the number of individual wheat stems). The architectural data consisted of information about the dimensions, orientations, and moisture contents of the individual canopy components, such as ears and leaves, as well as soil roughness and moisture. These data were sufficiently detailed to drive the RT2 radiative transfer model [10]. Results of the modeling have been published in [17] and were used to aid interpretation of the scattering processes observed in the data, but, for reasons discussed in the Introduction, we were unable to use them with confidence to interpret the measurements quantitatively.

Two particular canopies, on which radar measurements were made on June 18 and July 20, 1999, are considered here and are shown in Fig. 2. The measurements on June 18 took place just after ear emergence. The canopy was green and $58 \mathrm{~cm}$ tall; its gravimetric moisture varied between $71 \%$ and $80 \%$; and it had a shoot density of 441 shoots $/ \mathrm{m}^{-2}$. By July, the crop had an average height of $65 \mathrm{~cm}$, and its gravimetric moisture varied between $32 \%$ and $68 \%$. There were 604 shoots $/ \mathrm{m}^{2}$. The GAI was around 2.9 on both dates; soil properties were also similar, with an rms height of $1 \mathrm{~cm}$, while soil moisture was less than $10 \%$ during the June measurements and around $11 \%$ in July.

Although the pulse synthesis technique employed allows great flexibility in choice of frequency, the radar measurements presented here are restricted to $\mathrm{C}$ and $\mathrm{X}$ bands, at $\mathrm{VV}, \mathrm{HH}$, and VH polarizations, and cover incidence angles from $20^{\circ}$ to $50^{\circ}$. Backscatter measurements from the June and July canopies 


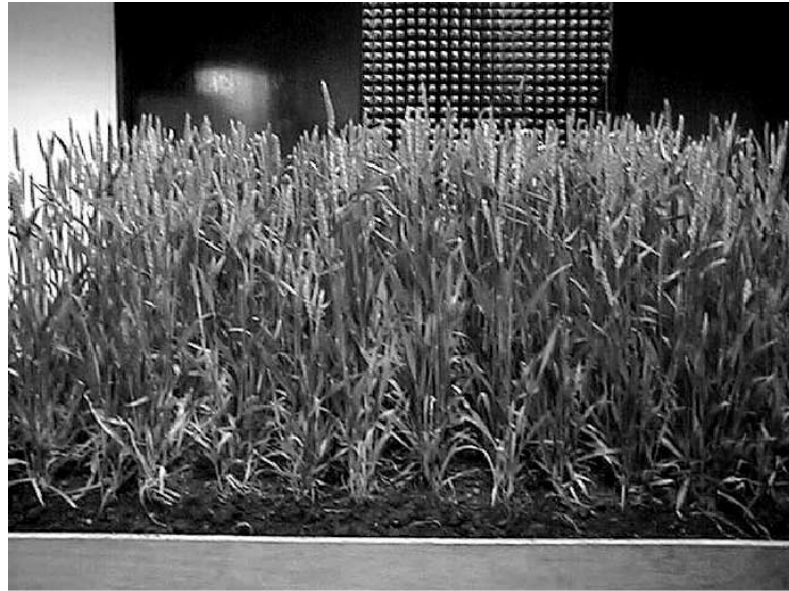

(a)

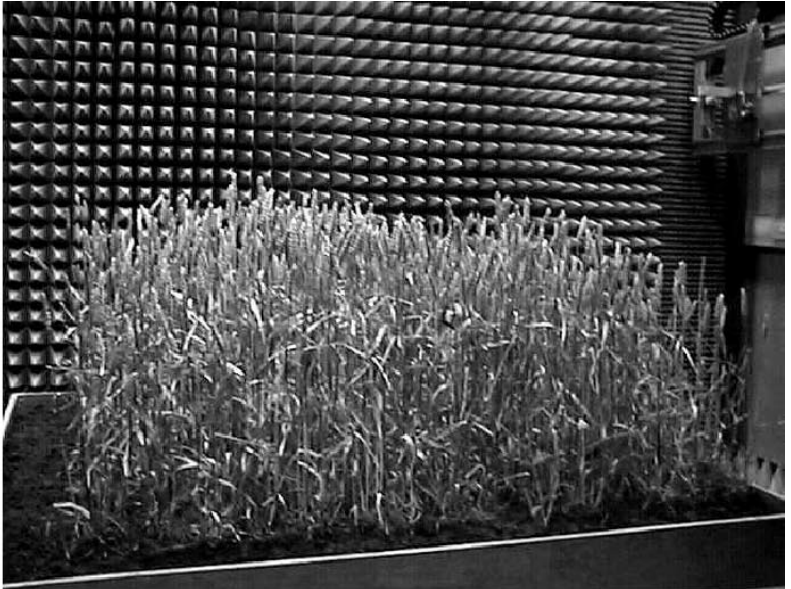

(b)

Fig. 2. Photographs of measured wheat canopies. (a) June 18, 1999. (b) July 20, 1999.
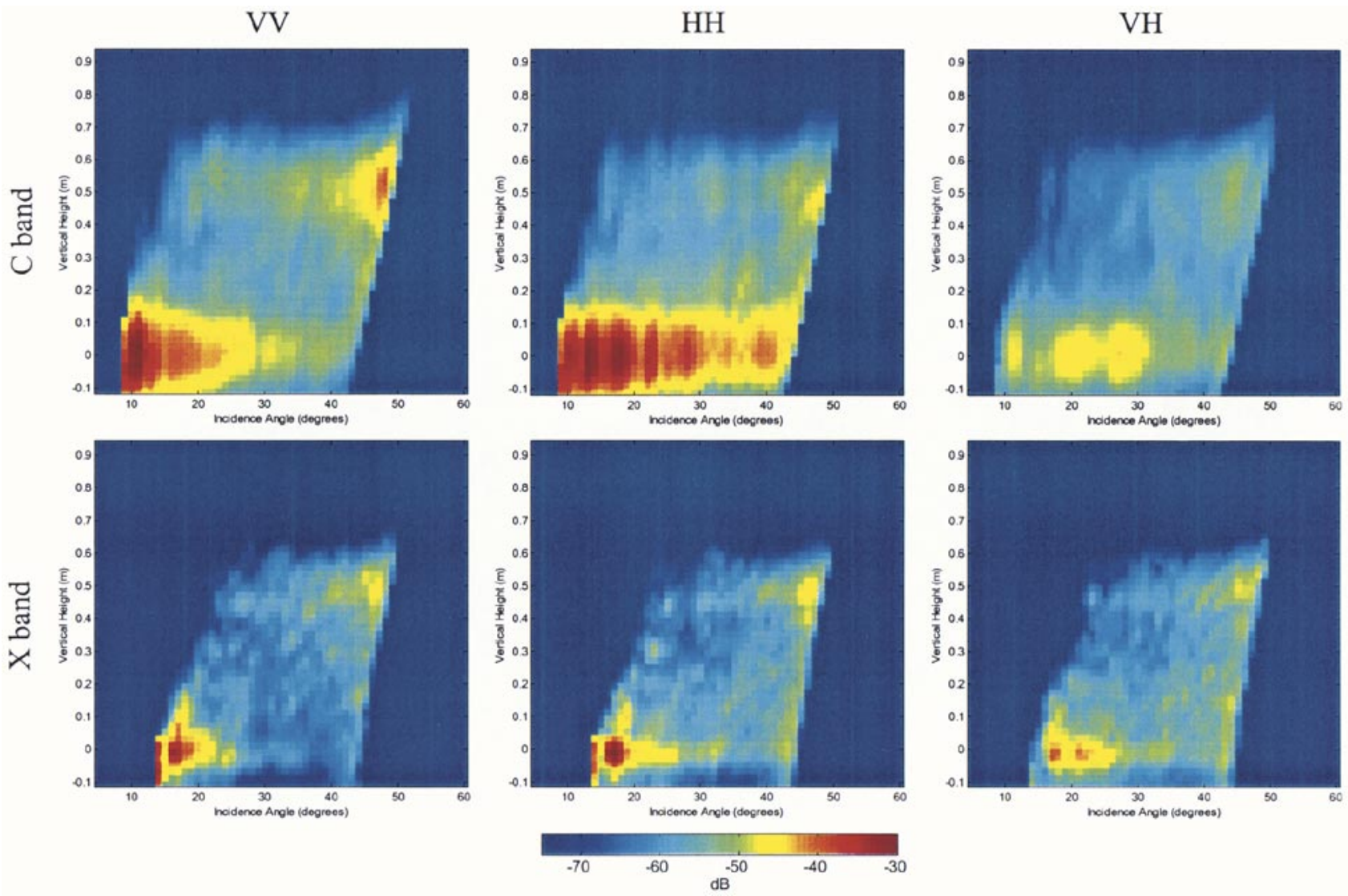

Fig. 3. Images of wheat canopy RCS measured on June 18 , for $\mathrm{C}$ and $\mathrm{X}$ bands at $\mathrm{VV}, \mathrm{HH}$, and VH polarizations.

are illustrated by Figs. 3 and 4, respectively. Incidence angle and height above the soil are shown on the horizontal and vertical axes, and the color scale indicates RCS (in decibels). Because the radar is close to the canopy, incidence angle varies with height, so that the imaged region does not appear rectangular. Note that these images are not individual slices through the 3-D dataset, but have been incoherently averaged in azimuth, at a given height and incidence angle, to bring out the overall scattering pattern more clearly. The number of independent samples averaged depends on the shape and size of the resolution cells, which vary with position; however, it always exceeds 15 .

Obvious in both Figs. 3 and 4 is the layered structure of the data. The lower layer corresponds to the attenuated soil return. Layers above the soil correspond to scattering from the canopy region. Note that soil returns at incidence angles less than $20^{\circ}$ have not passed through a complete canopy, since the radar scanning aperture is above and to the left of the canopy in each image. Complete canopy interaction only occurs for incidence angles exceeding that at the top of the front edge of the canopy 

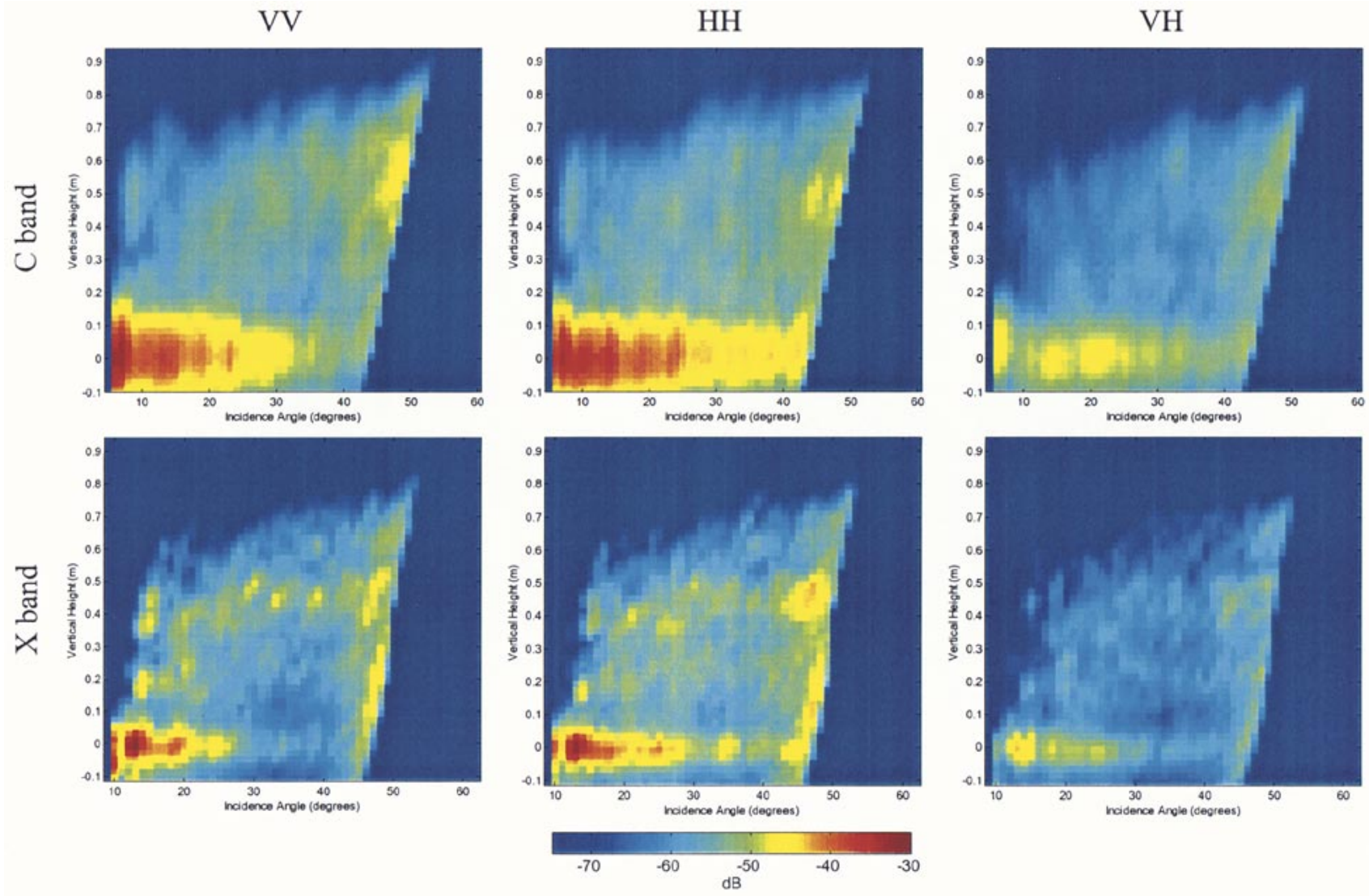

Fig. 4. Images of wheat canopy RCS measured on July 20, for C and X bands at VV, HH, and VH polarizations.

layer. At far range, the measurements are truncated to ensure that they lie completely within the canopy and to avoid any possible contamination by the antenna nulls.

It is important to realize that the observed values may contain a contribution from multiple scattering in addition to direct returns [22]. Canopy-ground bounce terms will appear at soil level and will be indistinguishable from the direct ground return. The location of second-order volume scattering events is dependent on the path length. Events associated with shorter path lengths will add to the direct scattering terms within the canopy; this may contribute to the rather diffuse volume scattering observed in, for example, the X-band VH results shown in Fig. 3. Events with long paths will be generated below the canopy and will, therefore, not be visible in the images.

In the C-band images for both measurement dates, the soil return dominates the backscatter at $\mathrm{HH}$ polarization for all incidence angles, but at VV is dominant only for angles less than $35^{\circ}$. This difference is explained by strong attenuation of the vertically polarized wave by the vertically oriented wheat stems on both the forward and return propagation paths [15]. Soil returns are also dominant at $\mathrm{VH}$ polarization for all but the largest angles. Since the direct cross-polarized backscatter from the soil is expected to be small, this probably indicates stem-ground double scattering. As noted above, these stem-ground returns will appear at ground level. Simulations with a second-order radiative transfer model [17] agree with this analysis, predicting that stem-ground terms and, to a lesser extent, ear-ground terms exceed the direct backscatter from the soil. The important point for parameter recovery is that the cross-polarized return is not dominated by volume scattering in the vegetation but is strongly affected by the soil (via canopy-ground bounce terms). At all polarizations, the soil return decreases with increasing incidence angle, as a result of both the incidence angle dependence of surface scattering and increasing attenuation as the path through the canopy gets longer. In contrast, direct canopy backscatter increases with increasing incidence angle. This is especially noticeable in the June measurements at VV polarization for angles greater than $40^{\circ}$, where the backscatter is generated by the flag leaves and/or ears. The July measurements do not show such a high level of backscatter from the upper canopy layer, due to the much lower gravimetric moisture content of the flag leaves and ears on that date.

The higher resolution in the X-band images of Figs. 3 and 4 allows more detailed visualization of the scattering. One quantitative difference between the $\mathrm{C}$ - and $\mathrm{X}$-band images arises from the higher attenuation at $\mathrm{X}$ band, which limits penetration into the canopy, causing the ground return to dominate the canopy backscatter only for angles less than $30^{\circ}$ at $\mathrm{VV}$ polarization. As at $\mathrm{C}$ band, ground scatter dominates out to higher incidence angles at $\mathrm{HH}$ than at VV. The VH return shows strong ground returns out to $35^{\circ}$, after which scattering appears to be distributed through the canopy, with the strongest returns from the flag leaf/ear layer.

There are marked differences between the X-band canopy backscatter in the June and July measurements. In June, canopy backscatter increases with increasing incidence angle at all po- 

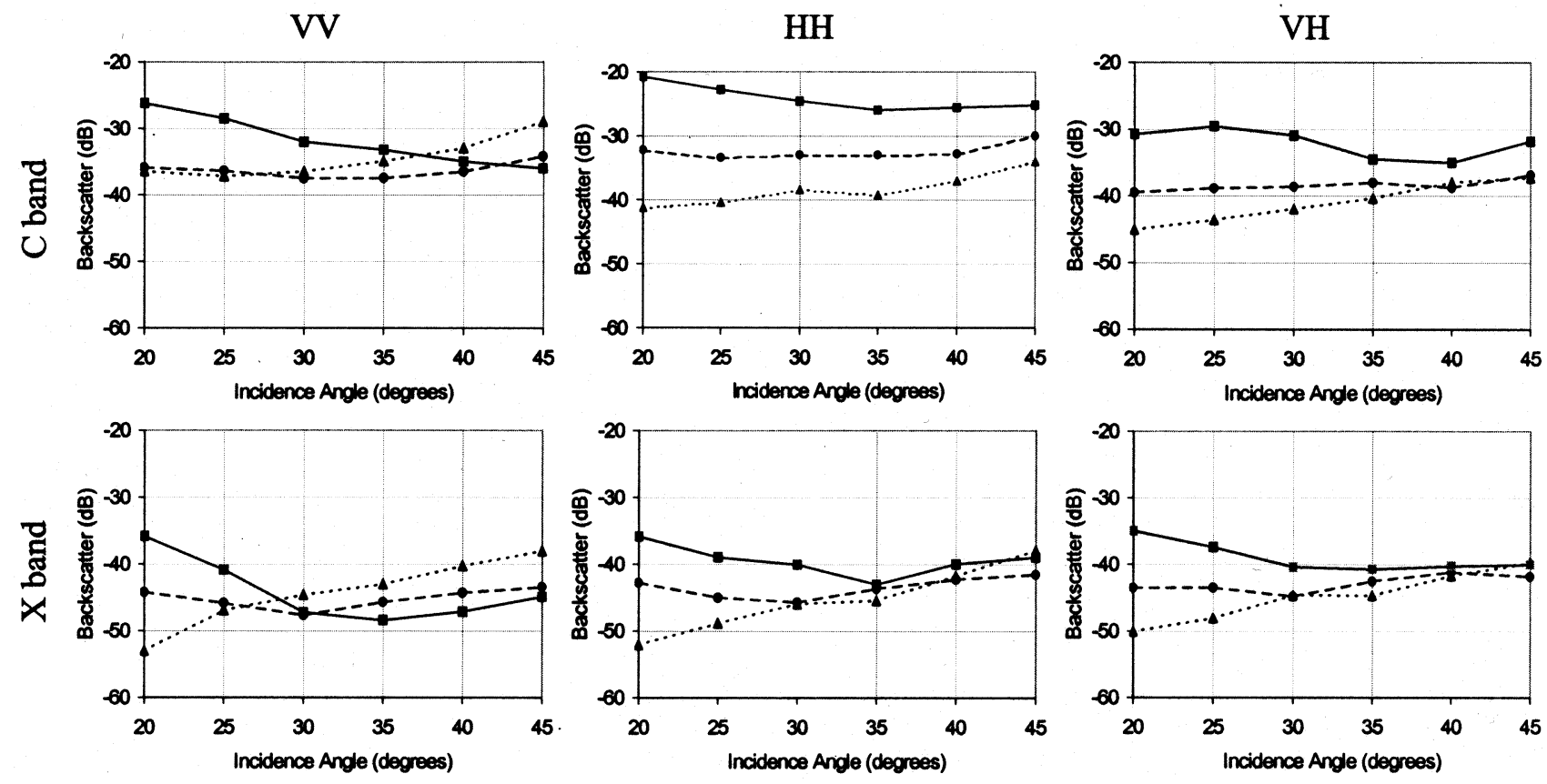

$\cdots-$ Upper Canopy $-\bullet-$ Lower Canopy $\rightarrow-$ Ground

Fig. 5. Total backscatter within layers for the canopy measured on June 18, 1999, at C and X bands, corresponding to Fig. 3. As noted in the text, the displayed backscatter values correspond to RCS, not backscattering coefficient.

larizations, but much less angular variation is visible in the July measurements. Instead, the July data show a clear scattering layer at a height of $\sim 40 \mathrm{~cm}$ for $\mathrm{VV}$ and $\mathrm{HH}$ polarizations for all incidence angles, which corresponds to the location of the flag leaf ligules. A second weaker layer at $\sim 20 \mathrm{~cm}$ corresponds to a lower layer of leaves. The importance of the leaves to the total $\mathrm{X}$-band canopy backscatter in July is not reproduced in model simulations [17], which predict that ear scattering dominates.

A useful way to synthesize the overall behavior of the images in Figs. 3 and 4 is by evaluating the integrated power from different parts of the canopy. This aids comparison with calculations by scattering models, most of which adopt a layeredmedium approach. For the images of Fig. 3, three layers are considered: an upper layer (for heights greater than $35 \mathrm{~cm}$ ) containing mostly flag leaves and ears, a lower layer containing the stems and remaining leaves with heights up to $35 \mathrm{~cm}$, and a soil layer. The powers from these layers for the data of Fig. 3 are shown in Fig. 5.

At $\mathrm{C}$ band, soil scatter is the dominant term for $\mathrm{HH}$ (via direct returns) and $\mathrm{VH}$ (through the double-bounce mechanism) for all incidence angles. However, for VV, the upper canopy dominates for angles exceeding $37^{\circ}$ due to increased interaction with the flag leaves and/or ears. This response explains the increase in total VV backscatter at angles greater than $40^{\circ}$, which has been observed in other experimental campaigns [23]. The power from the soil declines steadily with incidence angle at VV, falling by about $10 \mathrm{~dB}$ across the swath due to the angular dependence of the soil and due to increased canopy attenuation, primarily from the stems. At HH, where the interaction with the stems is not so strong, soil returns are less variable. After an initial decline of about $4 \mathrm{~dB}$, the ground return remains fairly constant.
The X-band measurements show the upper canopy becoming dominant at $\mathrm{VV}$ for angles greater than $28^{\circ}$. For $\mathrm{HH}$ and $\mathrm{VH}$, soil dominates out to $35^{\circ}$, after which the contributions from all three layers become comparable. Surprisingly, the soil return does not show monotonic behavior, but declines then increases for both $\mathrm{HH}$ and VV. The sharper decline at VV is the principal reason why the upper canopy becomes dominant at this polarization. The increase in the soil return is almost certainly due to a canopy-soil interaction, which cannot be separated from the direct ground return in these images. However, simulations with the RT2 model failed to produce this effect.

A similar analysis applied to the layers in Fig. 4 showed a reduction in the soil return between June and July for $\mathrm{VH}$ polarization at both $\mathrm{C}$ and $\mathrm{X}$ band. This is probably caused by decreased canopy-ground bounce terms, due to the drier nature of the canopy in July.

In summary, the results from the indoor measurements show the following.

1) Radar sees mature wheat canopies essentially as two- or three-layer media.

2) The soil return decreases relative to the canopy as incidence angle increases.

3) The canopy return dominates that from the soil out to greater incidence angles for $\mathrm{HH}$ than for $\mathrm{VV}$.

4) Scattering from the canopy is dominant over a greater range of incidence angles for $\mathrm{X}$ band than for $\mathrm{C}$ band.

5) The HV return is not dominated by volume scattering, but contains a very significant soil return.

Hence, for direct sensing of the vegetation, we should use $\mathrm{X}$ band (or higher frequencies), VV polarization, and large in- 

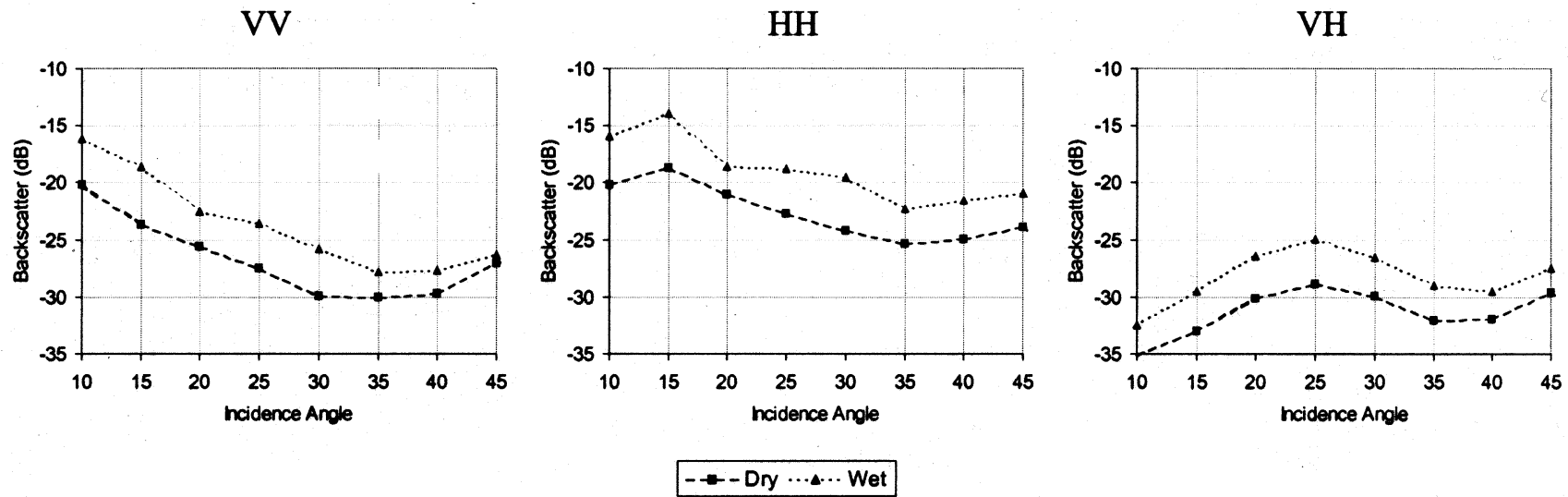

Fig. 6. Total C-band backscatter from a canopy measured on June 18, 1999, before and after wetting. As noted in the text, the displayed backscatter values correspond to RCS, not backscattering coefficient.

cidence angles. However, as we show below, these conclusions may not apply if our concern is the recovery of crop information.

Before leaving the indoor measurements, we note some important results from an experiment performed on June 18, when 21 liters of water (equivalent to $8 \mathrm{~mm}$ of rain) were sprayed over the canopy, using a watering can fitted with a rose to simulate the effect of rain. Fig. 6 compares the integrated C-band backscatter from the wet and dry canopies. Wetting causes increases of 3-5 dB for all polarizations and incidence angles, except for reduced differences in VV at the higher incidence angles. Detailed analysis reveals that most of the wet-dry variation occurs in the lower canopy and soil regions. The VV signal at large incidence angles is less sensitive to wetting because here the scattering comes mainly from the upper canopy (see Figs. 3 and 5).

\section{OUTDOOR MEASUREMENTS}

The GB-SAR facility includes a portable outdoor radar system mounted on a trailer-borne hydraulic lift [24] (Fig. 7). This system operates on the same principles as the indoor system, but with only a 4-m linear scanner, so it cannot perform 3-D imaging. This sensor can provide fully polarimetric measurements covering the frequency range from $\mathrm{X}$ to $\mathrm{L}$ band, over an area of typically $1000 \mathrm{~m}^{2}$.

During the 2000 growing season, trial plots of winter wheat (variety Claire) were provided by ADAS Consulting Ltd. on an experimental farm near Cambridge, U.K. By managing the plots in different ways, a wide range of shoot number, biomass, and GAI conditions were generated. The different management regimes included use of two drilling dates, two seed rates, and three different levels of applied nitrogen fertilizer. Identical levels of fungicides and herbicides, consistent with a normal commercial crop, were applied to each of the plots.

Accompanying the radar measurements were agronomic data (shoot number, fresh biomass, GAI, and growth stage) and architectural data, consisting of detailed information on the dimensions, orientations, and moisture content of all the components within the wheat canopy, i.e., leaves, stems, and ears. Soil roughness and moisture were also measured, along with crop height.

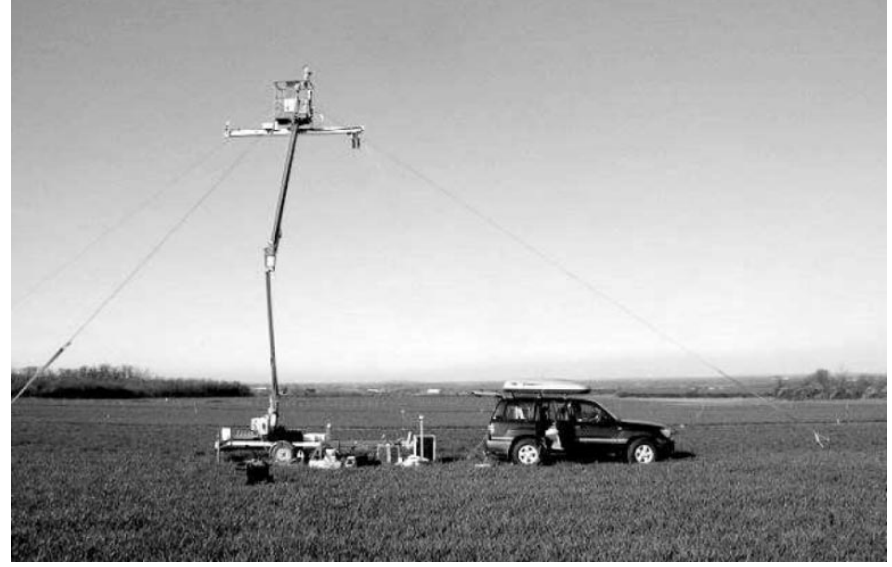

Fig. 7. Photograph of GB-SAR outdoor facility, with the linear scanner mounted on a 10-m-high hoist.

The most complete dataset was at $\mathrm{C}$ band, for which nine sets of measurements were collected on three trial plots on different dates. Issues connected with the antenna patterns meant that comparable coverage for all nine datasets was only possible at around $40^{\circ}$ incidence angle. Fig. 8(a) shows the average radar backscatter derived from these data against fresh biomass, for $\mathrm{VV}, \mathrm{HH}$, and VH polarizations. Backscatter decreases with increasing biomass for both $\mathrm{VV}$ and $\mathrm{VH}$ polarizations, but $\mathrm{HH}$ polarization exhibits little variation, except for one bare soil value early in the season. Similar trends were observed in comparisons between backscatter and GAI. Note that results in [9] also show similar behavior for comparable values of biomass.

Based on the indoor measurements discussed in Section II, but bearing in mind the wetter soils in the outdoor measurements, it is likely that the measured backscatter consists largely of an attenuated soil contribution. Consequently, biomass is being expressed through its effect on extinction, rather than by its contribution to direct canopy backscatter. Since soil attenuation is a measure through the whole canopy, it in a sense integrates the overall canopy biomass. The VV and $\mathrm{VH}$ returns are much more strongly affected by attenuation than $\mathrm{HH}$, hence their greater sensitivity to biomass. 

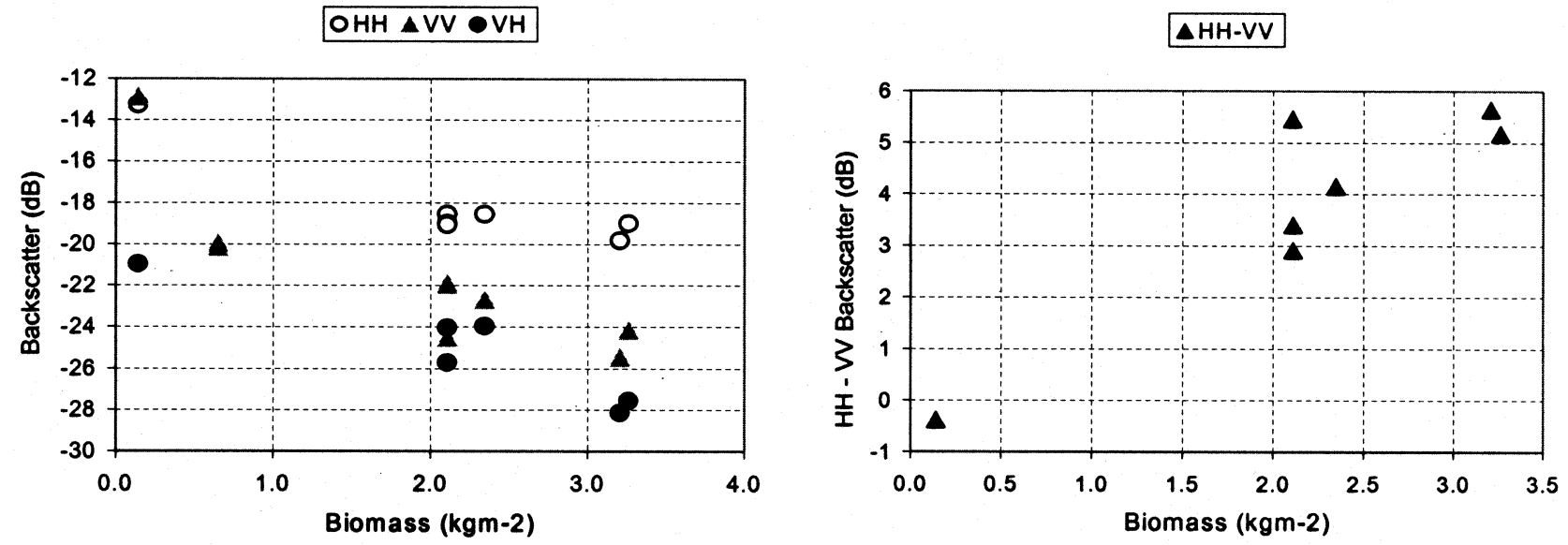

Fig. 8. Average C-band backscatter and HH-VV (in decibels) difference at $40^{\circ}$ incidence angle plotted against biomass. As noted in the text, the displayed backscatter values correspond to RCS, not backscattering coefficient.

A problem in using single-channel backscatter as a biomass indicator is implicit in Fig. 6: rainfall can cause large changes in the radar return, rendering the inversion unreliable. However, Fig. 6 also shows that the different channels exhibit very similar responses to wetting. This suggests that the difference particularly between the VV and HH backscatter might be a useful indicator of biomass. This relation is shown in Fig. 8(b). Not surprisingly, given the results shown in Fig. 8(a), the HH-VV amplitude difference increases sharply with biomass.

An unfortunate feature of Fig. 8 is the large gap in biomass values between 0.75 and $2 \mathrm{~kg} \mathrm{~m}^{-2}$, caused by poor weather conditions in April that rendered measurements impossible. This is the period of most rapid growth and increasing biomass. Furthermore, the measurements stop in early June, and hence all the measurements occur during the declining phase of the wheat growth curve, i.e., the plot of the wheat backscatter against time. The measurements do not continue into the increasing phase that normally follows [1], [10], [11]. This means that neither the overall shape of the plot of biomass against the HH-VV amplitude difference nor the limits of its sensitivity can be inferred from this dataset.

\section{DISCUSSION AND CONCLUSION}

The argument in Section III identifies differential attenuation of the soil return by the $\mathrm{HH}$ and VV channels as the key biomass indicator. Interchannel amplitude differences are preferred because they are less prone to disturbances from rainfall than single channels. The HH-VH amplitude difference could also be used, but suffers from greater sensitivity to noise (in the cross-polarized channel) and possible bad behavior under conditions of bare soil (or low biomass) due to very low values in the VH return. This argument, if its general validity can be demonstrated, has strong implications for the design of a system to be used for measuring biomass. The central requirement is that both the $\mathrm{HH}$ and VV returns are dominated by attenuated scattering from the soil. This requirement is more easily met at $\mathrm{C}$ band than at $\mathrm{X}$ band. Also, larger incidence angles should be used, since the difference between the HH and VV soil returns increases with incidence angle (due to increased path length through the canopy). However, as incidence angle increases, the VV return will at some point switch over to being dominated by the upper canopy (see Figs. 3 and 4), whereupon the relationship between biomass and the HH-VV difference will break down. The results in this paper suggest a transition point around incidence angles of $35^{\circ}$ to $40^{\circ}$, dependent on soil moisture conditions.

It can be seen that these conclusions are not the same as those in Section II, where the indoor measurements seemed to suggest $\mathrm{X}$ band, $\mathrm{VV}$, and large incidence angles as the preferred sensor characteristics for wheat sensing. However, this configuration principally measures a specific aspect of the canopy, namely the flag leaf layer, which may be only weakly related to more interesting agronomic properties. In contrast, the argument in Section III suggests that a two-channel C-band sensor operating at moderate incidence angles is most fitted to the task of biomass measurement.

The inferences above must be treated with some care, as there are weaknesses in the dataset on which they are based.

1) Only a small number of canopies were measured.

2) There were no measurements during the period of most rapid growth.

3) Insufficient $X$-band data were gathered to allow comparison with $\mathrm{C}$ band.

4) Only a single wheat variety was considered in each of the campaigns.

Scatterometer measurements indicate the importance of point 4). For example, in [4], significant differences were found between two different varieties of wheat. In particular, although both showed an approximately linear relationship between LAI and backscattering coefficient (at X band), the slope of this relation was quite different for the two varieties.

It is clear that more measurements are needed to address the shortcomings of the data described in this paper, but the work reported here provides a much better insight into which are the key questions. In particular, further experimental studies seem essential, including the following: 
1) investigation of the robustness of the $\mathrm{HH}-\mathrm{VV}$ amplitude difference as a biomass measure over the full biomass range of a developing crop;

2) comprehensive measurements at $X$ band.

The Envisat mission will allow the first of these to be carried out, while the second could be addressed by further GB-SAR outdoor measurements and/or airborne campaigns with X-band systems, such as E-SAR.

The value of the indoor measurements goes far beyond the averaged images shown in this paper. The full 3-D dataset can locate the scattering with sufficient spatial accuracy to assess the contribution from individual plant components. In combination with isolated component measurements and measurements of attenuation, this will allow the fundamental assumptions of the scattering models to be tested and to ensure that their descriptions of scattering processes conform to reality.

Finally, developments to the scattering models to remove their known deficiency as regards calculation of attenuation in wheat canopies are highly desirable. The lack of a reliable model significantly hampered the interpretation of the reported measurements. However, progress toward such a model presents a significant theoretical challenge [18].

\section{ACKNOWLEDGMENT}

The authors gratefully acknowledge experimental assistance from A. Race, D. Cox and A. J. McDonald. They would also like to thank P. Dampney and A. Gay (ADAS Consulting Ltd., U.K.) for providing the wheat canopies, and C. Anderson and R. Cordey (BAE Ssystems) for help in field measurements and advice on backscatter modeling.

\section{REFERENCES}

[1] T. Le Toan, A. Lopes, and M. Huet, "On the relationships between radar backscattering coefficient and vegetation canopy characteristics," in Proc. IGARSS, 1984, ESA SP-215, pp. 155-160.

[2] F. T. Ulaby and T. F. Bush, "Monitoring wheat growth with radar," Photogrammetric Eng. Remote Sens., vol. 42, no. 4, pp. 557-568, 1976.

[3] B. A. M. Bouman, "Crop parameter estimation from ground-based X-band ( $3 \mathrm{~cm}$ wave) radar backscattering data," Remote Sens. Environ., vol. 137, pp. 193-205, 1991.

[4] B. A. M. Bouman and H. W. J. van Kasteren, "Ground-based X-band (3 $\mathrm{cm}$ wave) radar backscattering of agricultural crops. II. Wheat, barley and oats: The impact of canopy structure," Remote Sens. Environ., vol. 34, pp. 107-119, 1990.

[5] A. Toure, K. P. B. Thomson, G. Edwards, R. J. Brown, and R. G. Brisco, "Adaptation of the MIMICS backscattering model to the agricultural context-Wheat and canola at L and C bands," IEEE Trans. Geosci. Remote Sensing, vol. 32, pp. 47-61, Jan. 1994.

[6] B. A. M. Bouman and D. H. Hoekman, "Multitemporal, multi-frequency radar measurements of agricultural crops during the Agriscatt- 88 campaign in the Netherlands," J. Remote Sens., vol. 14, no. 8, pp. $1595-1614,1993$

[7] P. Ferrazzoli, S. Paloscia, P. Pampaloni, G. Schiavon, S. Sigismondi, and D. Solimini, "The potential of multifrequency polarimetric SAR in assessing agricultural and arboreous biomass," IEEE Trans. Geosci. Remote Sensing, vol. 35, pp. 5-17, Jan. 1997.

[8] P. Ferrazzoli, L. Guerriero, and G. Schiavon, "Experimental and model investigation on radar classification capability," IEEE Trans. Geosci. Remote Sensing, vol. 37, pp. 960-968, Mar. 1999.

[9] G. Macelloni, S. Paloscia, P. Pampaloni, F. Marliani, and M. Gai, "The relationship between the backscattering coefficient and the biomass of narrow and broad leaf crops," IEEE Trans. Geosci. Remote Sensing, vol. 39, pp. 873-884, Apr. 2001.
[10] G. Cookmartin, P. Saich, S. Quegan, R. Cordey, P. Burgess-Allen, and A Sowter, "Modeling microwave interactions with crops and comparison with ERS-2 SAR observations," IEEE Trans. Geosci. Remote Sensing, vol. 38, pp. 658-670, Mar. 2000.

[11] P. Saich and M. Borgeaud, "Interpreting ERS SAR signatures of agricultural crops in Flevoland, 1993-1996," IEEE Trans. Geosci. Remote Sensing, vol. 38, pp. 651-657, Mar. 2000.

[12] E. P. W. Attema and F. T. Ulaby, "Vegetation modeled as a water cloud," Radio Sci., vol. 13, no. 2, pp. 357-364, 1978.

[13] T. Le Toan, "Scatterometer measurements on crop and soil surfaces," in Proc. ESA-EARseL Workshop, Alpbach, Austria, Mar. 1981, ESA SP-166, pp. 99-110.

[14] T. Le Toan, A. Lopes, and A. Malavaud, "Relations entre le coefficient de retrodiffusion radar et les caracteristiques d'un couvert vegetal: Considerations sur l'effet de la structure," in Proc. Signatures d'Objets en Teledetection, Bordeaux, France, 1983, pp. 601-615.

[15] A. Lopes and T. Le Toan, "Effet de la polarization d'une onde electromagnetique dans l'attenuation de l'onde dans un couvert vegetal," in Proc. 3rd Int. Coll. Spectral Signatures in Remote Sensing, Les Arcs, France, 1985, ESA SP-247, pp. 117-122.

[16] M. Bracaglia, P. Ferrazzoli, and L. Guerriero, "A fully polarimetric multiple scattering model for crops," Remote Sens. Environ., vol. 54, pp. 170-179, 1995.

[17] S. C. M. Brown, G. Cookmartin, K. Morrison, A. J. McDonald, S Quegan, C. Anderson, R. Cordey, and P. Dampney, "Wheat scattering mechanisms observed in near-field imagery compared with results from a radiative transfer model," in Proc. IGARSS, Honolulu, HI, 2000, pp. 2933-2935.

[18] G. Picard, T. Le Toan, F. Mattia, A.-M. Gatti, F. Posa, A. D’Alessio, C. Notarnicola, and E. Sabatelli, "A backscatter model for wheat canopies. Comparison with C-band multiparameter scatterometer measurements," in Proc. 3rd Int. Symp. "Retrieval of Bio- and Geo-Physical Parameters from SAR Data for Land Applications”, Sheffield, U.K., 2001, ESA SP-475, pp. 291-296.

[19] K. Morrison, J. C. Bennett, G. Cookmartin, A. J. McDonald, A. Race, and S. Quegan, "Three-dimensional X-band SAR imaging of a small conifer tree," Int. J. Remote Sens., vol. 22, no. 4, pp. 705-710, 2001.

[20] J. C. Bennett and K. Morrison, "Development of a ground-based, polarimetric synthetic aperture radar," in Proc. IEEE Aerospace Applications Conf., Los Alamitos, CA, 1996, pp. 139-146.

[21] K. Sarabandi, F. T. Ulaby, and M. A. Tassoudji, "Calibration of polarimetric radar systems with good polarization isolation," IEEE Trans. Geosci. Remote Sensing, vol. 28, pp. 70-75, Jan. 1990

[22] S. C. M. Brown and J. C. Bennett, "High-resolution microwave polarimetric imaging of small trees," IEEE Trans. Geosci. Remote Sensing, vol. 37, pp. 48-53, Jan. 1999

[23] F. Mattia, A.-M. Gatti, F. Posa, A. D’Alessio, C. Notarnicola, E. Sabatelli, M. Rinaldi, G. Satalino, G. Pasquariello, T. Le Toan, G. Picard, and M. Davidson, "Radar and ground measurements on wheat fields over the Matera site: An experimental study," in Proc. 3rd Int. Symp. "Retrieval of Bio- and Geo-Physical Parameters from SAR Data for Land Applications", Sheffield, U.K., 2001, ESA SP-475, pp. 279-284.

[24] J. C. Bennett, K. Morrison, A. M. Race, G. Cookmartin, and S. Quegan, "The UK NERC fully portable polarimetric ground-based synthetic aperture radar (GB-SAR)," in Proc. IGARSS, Honolulu, HI, 2000, pp. 2313-2315.

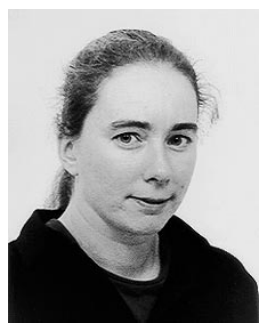

Sarah C. M. Brown received the M.Eng. degree in electrical and electronic engineering from the University of Newcastle, Newcastle, U.K., in 1995, and the Ph.D. degree in high resolution radar imagery from the University of Sheffield, Sheffield, U.K., in 1999.

Until 2001, she was a Research Associate with the University of Sheffield, working on the retrieval of biophysical parameters from wheat canopies using high-resolution ground-based SAR systems. She is currently with the Advanced Technology Centre, BAE Systems, Chelmsford, U.K., where her primary research interest is retrieval of information from SAR imagery and the development of SAR techniques for a variety of different land applications. 


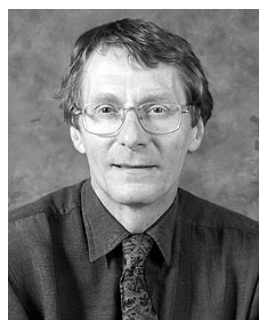

Shaun Quegan (M'90) received the B.A. and M.S. degrees in mathematics from the University of Warwick, Coventry, U.K., in 1970 and 1972, respectively, and the Ph.D. degree from the University of Sheffield, Sheffield, U.K., in 1982

From 1982 to 1986, he was a Research Scientist with the Marconi Research Centre, Great Baddow, U.K., and led the Remote Sensing Applications Group from 1984 to 1986 . He established the SAR Research Group at the University of Sheffield in 1986, whose success led to his Professorship awarded in 1993. In the same year, he helped to inaugurate the Sheffield Centre for Earth Observation Science, of which he remains the Director. In 2001, he became the Director of the U.K. National Environmental Research Council Centre for Terrestrial Carbon Dynamics (CTCD). This multiinstitutional center is concerned with assimilating earth observation and other data into process models of the land component of the carbon cycle. His broad interests in the physics, systems, and data analysis aspects of radar remote sensing are now subsumed in the more general aim of exploiting EO technology to meet the needs of the CTCD.

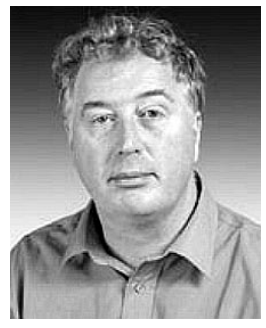

Keith Morrison (M'97) received the B.S. degree in physics with astrophysics from the University of Leicester, Leicester, U.K. in 1983, and the Ph.D. degree in astronomy and astrophysics from the University of St. Andrews, St. Andrews, U.K., in 1987.

From 1987 to 1994 , he was with the British Antarctic Survey, Cambridge, U.K., carrying out research in space plasma physics. Between 1994 and 2000, he was at the University of Sheffield, Sheffield, U.K., which included a three-year role as Programme Manager of the GB-SAR project. From 2000 to 2002, he was with the U.K.'s Defence and Evaluation Research Agency, Malvern, involved in the RCS measurement of radar stealthy platforms. Since 2002, he has been a Senior Lecturer at the Royal Military College of Science, Cranfield University, Shrivenham, U.K. His research interests include the development, application, and modeling of ground-based synthetic aperture radar techniques applied to environmental remote sensing. Of particular interest is the problem of imaging wind-blown vegetation, and 3-D SAR tomography.

Dr. Morrison received the National Aeronautics and Space Administration's Group Achievement Award in 1998, and in 2002, he received the Taylor and Francis and Remote Sensing and Photogrammetry Society's Best Letter Award for the publication "Three-dimensional X-band SAR Imaging of a Small Conifer Tree."

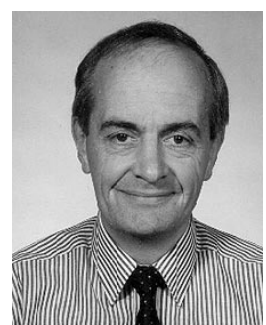

John C. Bennett received the B.Eng. and Ph.D. degrees from the University of Sheffield, Sheffield, U.K., in 1970 and 1974, respectively.

He has been with the Department of Electronic and Electrical Engineering, University of Sheffield, since 1972, where he has been a Lecturer, Senior Lecturer, and Reader. His primary research interest involves the development of a ground-based synthetic aperture radar system for the study of vegetation communities and environmental parameters. Other research interests include microwave holographic antenna measurements, near-field/far-field transformation techniques, the evaluation of microwave anechoic chambers and far-field ranges, and the free-space measurement of high-loss materials at microwave frequencies.

Dr. Bennett was a recipient of the Best Paper Award and the Best Applications Paper Award for a paper published in the 1976 IEEE TRANSACTIONS ON ANTENNAS AND PROPAGATION. In 1988, he was awarded the U.K. IEE Electronics Division Premium and, in 2001, received the Best Letter Award for a publication in the International Journal of Remote Sensing.

Geoff Cookmartin received the B.A. degree in electrical sciences from Trinity College, Cambridge, U.K., in 1981, and the M.S. degree in biophysics and bioengineering from the University of London, London, U.K., in 1983.

He was a Researcher in medical physics and subsequently in climate modeling before joining the Sheffield Centre for Earth Observation Science, Sheffield, U.K., where he worked on modeling and direct measurements of radar interaction with agricultural crops. 